\title{
Editorial
}

\section{Marketing's future matrix}

I watched the first Matrix film the other day for probably the fifth time. It is indeed a film well ahead of its time. It depicts a computer-generated world - a programme which controls all of us and in which we are all prisoners. The reality is the matrix, which none of us can see. I wonder in 50 years' time how far future technology, with its ability to create cyberworlds, will have changed the practice of marketing. Will we all be promoted products/services through a cyberworld and the dominance of the physical objective disappear?

Ian Pearson's opening Opinion Piece presents a shorter-term perspective, but does throw up some imaginative uses of the combination of physical products with online marketing services. By adding cyberspace functionality to any object, it can open whole new markets. It is as if suddenly an object has two separate lives - one in the real world and one in the computer.

The kind of new marketing technology will go all the way into the shopping experience. As Pearson says, 'Imagine a shopping booth in a corner shop lined with displays. A shopper in the booth could be immersed in a full virtual reality version of any store anywhere in the world.'

Back to the future with a bump, our first paper, by Richard Webber, is concerned with designing geodemographic classifications to meet contemporary business needs. As the expert in geodemographic classifications, Richard presents evidence to suggest that neighbourhood often contributes incremental predictive power in behavioural models over and beyond individual-level characteristics. Richard concludes with eight trends of particular relevance to marketers.

Leslie de Chernatony and George Christodoulides' paper discusses the challenges of online branding. The argument is raised whether brands online are different from brands offline. The authors argue the difference lies in the way the brand promise is executed. The example of the Co-op Bank is interesting, where the reassuring 'tone of voice' and the animated smile, among other aspects of the site, reinforce the brand values of responsible and caring, enabling a similar promise to be perceived between the offline and online brand.

Hugh Wilson et al. complete the papers with a method to optimise multiple channels. This is a very topical paper, particularly in B2B marketing, which in my view is still stuck in 'silo' product marketing. Today's marketers are faced with a bewildering mix of IT-enabled channels to the customer - websites, e-mails, call centres and so on - to complement traditional channels. The strategic question is not which channel to use, but which channel combination, as generally the customer is best served through a choice of channels. The authors go further and suggest a new synthesis of channel strategy tools. If channel choice is an issue you are currently confronting, this paper is well worth reading. (A supplementary paper by Janet Winston, on CRM in financial services, is available online at www.theidm.com or www.henrystewart.com/journals/im.)

Our Case Study, the SilverMinds catalogue - a special-interest catalogue marketing nostalgic and special-interest music - is a classic example of how RFM segmentation can be applied in a straightforward fashion and bring benefits and return on investment to a company.

Finally, our New Technology Briefing by William Conway gives a clear overview of the potential of kiosks. Having explained how they work, William goes on to debate whether they are hype or hope. As he concludes, technology advances the possibilities for transactions, information and promotion through kiosks and this will only be limited by the imagination of marketers who employ them. An apt note to finish on, I think.

Derek Holder 